\title{
La novelística de Vargas Llosa en la literatura-mundo: una mirada desde la teoría de los polisistemas
}

\section{Vargas Llosa's Novels in World Literature: An Approach From the Theory of Polysystems}

\author{
Carlos Arámbulo López \\ Universidad Nacional Mayor de San Marcos
}

\begin{abstract}
RESUMEN
Este artículo presenta las variantes en las novelas post boom de nuestro Nobel, desde la perspectiva de la teoría de los polisistemas, desarrollada por Itamar Even-Zohar. Parte de una periodización de las novelas de MVLI, teniendo como punto de corte la muerte de la poética de las vanguardias, descrita por Eric Hobsbawm. Desde esta divisoria de aguas distinguimos una poética de vanguardia y otra contemporánea, que se replican en la obra de Vargas Llosa a partir de su inclusión dentro del canon de la llamada literatura-mundo (Weltliteratur). Esta variación se evidencia por variantes en el repertorio compartidas con la novela contemporánea posmoderna, y se hacen explícitas en la variación de la perspectiva del narrador, asunción de la cultura de masas, la concepción del tiempo y su representación en la novela, y el auge de la narratividad sobre la literariedad.
\end{abstract}

\section{Palabras clave:}

Vargas Llosa / Literatura posmoderna / Teoría de los polisistemas / Literatura mundial

\section{ABSTRACT}

This paper presents the changes in Mario Vargas Llosa (MVLI) novels writen in his "post boom" period compared with his more representative works of the 60-70's following Itamar Even Zohar's Polysystem Theory. The author presents a periodization of MVLI novels asuming as a cornerstone what Eric Hobsbawm called "the death of vanguards' poetics". From this perspective, this paper differentiates two poetics, one vanguardist and another contemporary. Both are replicated in Vargas Llosa's works from his inclusion in the World Literature canon (Weltliteratur). Variations in repertory according to what we call postmodern literature affect the author's contemporary poetics. Some of the noticeable adjustments are: narrator's perspective, assumption of mass culture elements, time representation in the fictional universe and the preeminence of narrativity over literacy.

\section{Keywords:}

Vargas Llosa / Posmoderm Literature / Polysystem Theory / World Literature

\section{El problema de la periodización de la narrativa de MVLI}

Me gustaría iniciar estas reflexiones con una petición de principio: la periodización de la obra de cualquier autor obedece, en gran medida, a un criterio de orden impuesto para facilitar la lectura de su proceso poético y de sus mutaciones retóricas e ideológicas. Para este fin, los límites del espectro de marcos teóricos son el inmanentismo textual y el determinismo sociologizante. Entre ambos se abre un amplio espacio en el cual podemos hallar aportes tan dispares como la sociocrítica y la semiótica tensiva. Una dificultad adicional surge cuando se trabaja con la obra de un autor en plena producción; el aporte reflexivo cumple una suerte de rol premonitorio. Nada impide que el autor materia de estudio retome alguna vertiente ya anotada como superada y la desarrolle con mayor amplitud, dejando de lado aquello 
que nos parecía un camino firme y perdurable.

La aproximación desde una perspectiva única, con un recurso único, por lo tanto, es difícil; compartimos el convencimiento de que cada texto se presta a un enfoque definido a partir de su propia naturaleza, pero es factible añadir herramientas que aporten a la que aparece como idónea, para ofrecer una lectura lo más exhaustiva posible y rendir cuenta del mayor número de ondas que forma cada texto al ingresar al mar de la literatura.

Para José Miguel Oviedo (1982) existe una primera etapa formativa, que corresponde a su narrativa breve y que remataría con la publicación de Los jefes. Luego, una etapa de madurez en la cual pone en juego su mayor variedad de recursos estilísticos, la etapa más faulkneriana de Vargas Llosa, que inicia con La ciudad y los perros (1963) y culmina con Conversación en La Catedral (1969). Una tercera etapa (segunda de su producción novelística, para seguir el conteo de Oviedo) se inicia con Pantaleón y las visitadoras (1977) y se caracteriza por la irrupción del humor. La última edición del estudio de Oviedo llega hasta La guerra del fin del mundo (1981), en tanto novela, y cierra con una revisión de la producción crítico-teórica y teatral, a la fecha, de Vargas Llosa.

García-Bedoya, en Posmodernidad narrativa en América Latina (2012), esboza una periodización de la narrativa de Vargas Llosa, atendiendo a la irrupción en ella de la estética posmoderna. Señala un primer periodo en el cual Vargas Llosa termina siendo "uno de los grandes exponentes de la Nueva Novela Latinoamericana y de sus más audaces experimentos técnicos. Esta fase, que abarca su producción publicada en la década del 60, va de La ciudad y los perros, a Conversación en La Catedral' (p. 122). Oviedo dife- rencia producción novelística y cuento; por ello no incluye Los jefes. Luego identifica una segunda fase.

En la década de los setenta su obra experimenta importantes transformaciones, paralelas a las sufridas en otros planos por el sujeto productor. En esta segunda fase va adhiriendo lentamente a los postulados posvanguardistas. Primero, en Pantaleón y las visitadoras intenta una narración de mayor sencillez, incorporando el humor y la parodia. Este desplazamiento culmina en La tía Julia y el escribidor, donde la incorporación de la cultura de masas se hace patente a todos los niveles. (p. 122)

Vemos claramente que, de las posibles caracterizaciones acerca de la narrativa posmoderna - García-Bedoya prefiere emplear el término posvanguardista y solo menciona aquellas de raigambre cultural (accesibilidad del texto e incorporación de la cultura de masas)-, sin ingresar al terreno propiamente retórico estilístico, se incorpora una tercera característica, más retórica en el sentido de estructura e intencionalidad del discurso:

La opción por el posvanguardismo lo conducirá a explorar la otra faceta narrativa central de esta vertiente, la de la novela histórica, alcanzando, como lo destacó generosamente su adversario ideológico Ángel Rama, altas cotas de excelencia estética. La guerra del fin del mundo es sin duda el exponente más relevante en América Latina de esta opción por la novela histórica. (pp. 122-123).

García-Bedoya precisa, con corrección, que el posvanguardismo de la novela histórica y, por extensión, de La guerra del fin del mundo, se define como la opción del remake (y todas las variantes de neo identificables), caracte- rística que podría englobarse dentro de la más general, de adopción o inclusión de la cultura de masas. Esta lectura es coherente con su selección de los rasgos determinantes de la narrativa posvanguardista que son para él "el privilegio de la trama ${ }^{1}$ y el diálogo con la cultura de masas" (García-Bedoya, 2012, p. 119).

Desde nuestro punto de vista existirían tres grandes periodos: i) un periodo formativo, que incluye los cuentos publicados individualmente y en conjunto (Los jefes) y la primera novela (La ciudad y los perros) como su culminación; ${ }^{2}$ ii) un segundo momento, caracterizado por una mayor riqueza de recursos, un manejo de los tiempos sobrepuestos, inicio del empleo de las técnicas de los vasos comunicantes y diálogos telescópicos que se inicia con Los cachorros y termina en Conversación en La Catedral, la obra de mayor complejidad estructural y más cercana, después de La guerra del fin del mundo, al concepto de novela total. En la tercera etapa ingresa la cultura de masas como referente y se minimiza la relativización de los puntos de vista y se privilegia el trabajo secuencial de la historia. Se inicia con Pantaleón y las visitadoras (1977), con permanencia de los recursos de la etapa previa como poética residual, y continúa hasta el momento presente (2016, en que se redacta este texto). En esta tercera etapa las novelas exhiben rezagos de recursos de la etapa anterior, que hacen de este periodo posmoderno 0 posvanguardista uno sui géneris, ya que el autor intenta acceder al mercado amplio de lectores sin abandonar del todo sus marcas de estilo ni sus obsesiones de larga data, como su apego a la novela total (La guerra del fin del mundo) y biográfica (El sueño del celta, El paraíso en la otra esquina) y el gusto por las versiones y repeticiones, una lectura circular del tiempo en la cual los hechos del pasado se reeditan en el presente, que podemos encontrar

1 Algo que nosotros llamaremos "narratividad" del texto, una preocupación consciente por hacer que el relato fluya.

2 Sobre la exclusión de La ciudad y los perros del grupo de novelas del periodo vanguardista de MVLI, señalamos dos argumentos: Primero, la experimentación a nivel estructural es mínima: solo una secuencia de diálogo telescópico. Segundo, la marcada influencia flaubertiana, no faulkneriana, en cuanto al desenvolvimiento de la trama y del manejo del tiempo narrativo. Esta discusión, por demás extensa, es materia de estudio aparte. 
incluso en obras muy recientes (EI héroe discreto).

Eric Hobsbawm denomina muerte de las vanguardias al periodo que se inicia, cronológicamente, después de la segunda guerra mundial, alrededor de 1950, y que se acelera cuando se pasa de la lógica de la evolución del arte a la del que se acelera cuando se pasa de la lógica de la evolución del arte a la del consumo masivo, alrededor de los años sesenta, años en los cuales la tecnología trajo el arte a la vida cotidiana (un acercamiento a los postulados de la Escuela de Frankfurt) y, además, según Hobsbawm, "transformó su percepción” (1999, p. 497).

La modernidad presuponía que el arte era progresivo $y$, por consiguiente, que el estilo de hoy era superior al de ayer. Había sido, por definición, el arte de la 'vanguardia', un término que entró en el vocabulario de los críticos hacia 1880. Es decir, el arte de unas minorías que, en teoría, aspiraba a llegar a las mayorías, pero que en la práctica se congratulaban de no haberlo logrado aún. (p. 509)

La modernidad en el arte se identifica con la vanguardia; esta se derrumba cuando la masificación de la cultura impone el horizonte de expectativas por encima del evolucionismo estético de los autores de la vanguardia, ensimismados en producir obras y textos que el público masificado difícilmente podría elegir o preferir. Esto es, permitiendo el acceso de la poética de la cultura de masas al mundo de la gran literatura o el gran arte, en general. Para entender, desde la teoría de los polisistemas, la consolidación de esta nueva condición del mercado de la literatura, sería central el aporte de los estudiosos de la estética de la recepción.

\section{Perspectiva de los polisistemas de cultura}

La teoría de los polisistemas es, en esencia, una continuación del funcionalismo dinámico, pero más que ello, incorpora también categorías de otros investigadores, como la noción de campo, propuesta por Bourdieu (2011 [1995]) y el concepto de semiósfera de luri Lotman (1998). En buena cuenta, la propuesta de autores como los citados proporcionó a la teoría de los polisistemas "conceptos de modelización del mundo y de semiósfera, que en su conjunto constituyen la cultura, es decir, una serie de instrumentos de comprensión que permiten la vida social" (Even-Zohar, 1999, p. 27).

La teoría de los polisistemas ve la cultura como un sistema global que permite a los humanos poner en funcionamiento parámetros para organizar la vida en sociedad, no solamente bajo una perspectiva pasiva de comprensión, sino también como una acción, un actuar que da forma a la cultura. A escala reducida, al hablar de un sistema aislado, como, por ejemplo, el sistema literario, este sistema cultural global

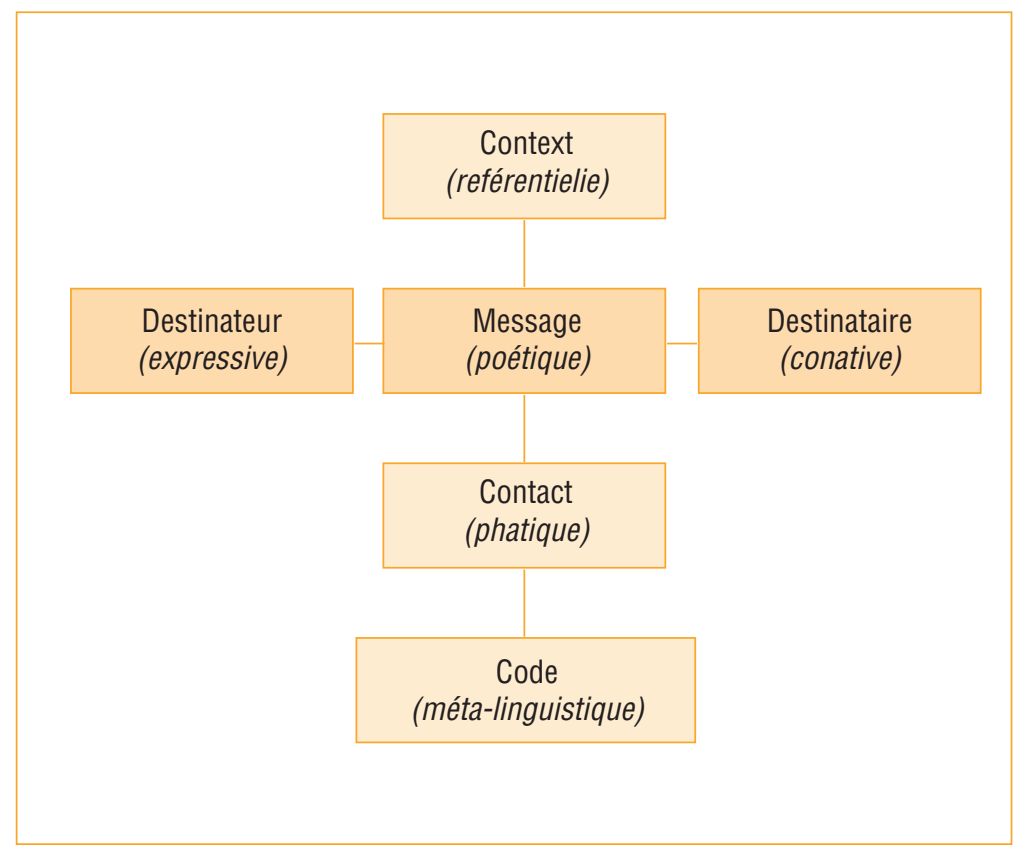

... y que Even-Zohar parafrasea de la siguiente manera:

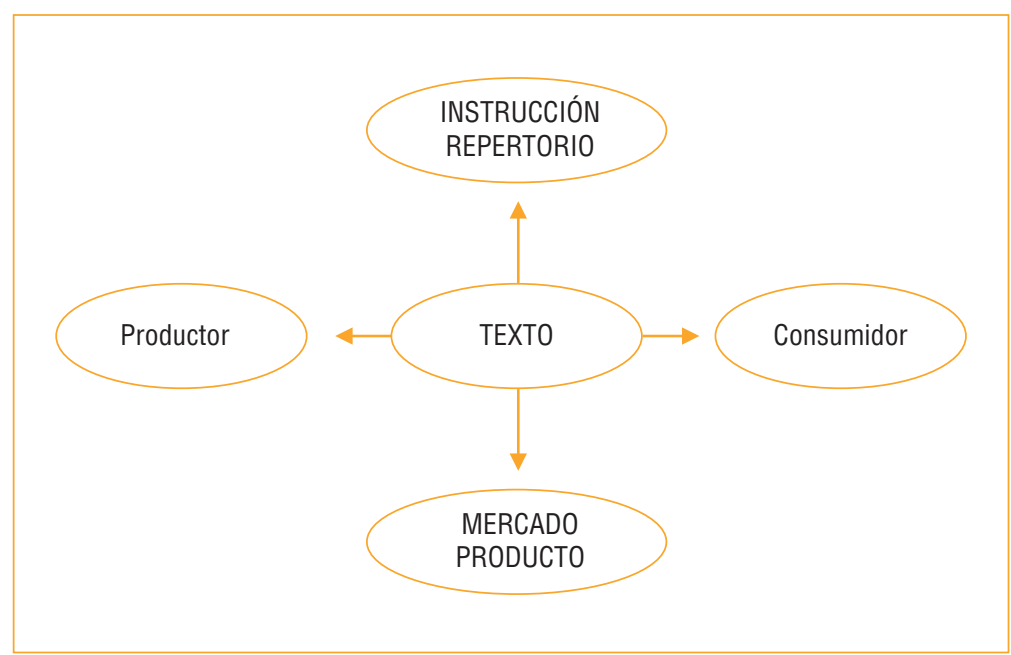

3 Este mismo esquema se emplea en la teoría de administración de empresas y mercados para explicar las cuatro P del marketing, Plaza (Mercado), Producto, Precio y Promoción. El precio es una variante generada por el juego entre mercado y promoción, lo que da origen a ese plus de valor que Marx no podía explicar en su estudio sobre la mercancía. Ahora sabemos que el plus de valor, equivalente al plus de goce lacaniano, lo genera la promoción (marketing). 
ayuda a estos sujetos en sociedad a delimitar qué se va a entender como literatura. La lingüística ha definido algunos componentes esenciales del marco teórico sistémico a partir del esquema de la comunicación propuesto por Jakobson ${ }^{3}$...

La novedad en el esquema que introduce Even-Zohar es la consideración de repertorio e institución, que constituye su vínculo con Pierre Bourdieu. Este esquema no representa una estructura, sino un sistema. Los sistemas suponen una red de interdependencias, de modulaciones mutuas, mientras que las estructuras son estables y universales, poco mutables. De ahí el apego del estructuralismo a la formulación, al lenguaje formal tomado de la lógica proposicional. Desde una posición sistémica se puede comprender mejor el funcionamiento de conformaciones sociales que se siguen autoconstruyendo en el mismo momento de ser analizadas. Es una manera de superar ese entrampamiento del estructuralismo, expresado en la díada sincronía - diacronía, y, también, una puerta de acceso a la comprensión de constructos teóricos móviles, como el concepto de campo desarrollado por Bourdieu (1995).

Teniendo como objetivo la definición de la composición del repertorio, podemos definir dos componentes centrales que Even-Zohar denomina los elementos y los modelos (Even-Zohar, 1999, p. 34). Los elementos individuales son equiparados a lo que en lingüística se reconoce como morfemas y lexemas. Para ellos Even-Zohar ha acuñado la categoría repertorema, que designa a cualquier miembro de un repertorio $\mathrm{y}$, en consecuencia, llama culturema a los repertoremas de una cultura. Respecto de los modelos, los concibe como una combinación que se hace posible a partir del preconocimiento de las posiciones en que podrían insertarse los elementos en la red de distintos modelos. Los define señalando que

analíticamente los modelos consisten en la combinación de elementos + reglas + las relaciones sintagmáticas que se imponen sobre el producto. Si el producto en cuestión es un evento, un suceso, entonces su modelo significaría la suma de los elementos + las reglas aplicables a dicho tipo de acontecimiento + las relaciones potenciales que pueden llevarse a cabo durante el hecho concreto. (Even-Zohar, 1999, p. 35)

Este preconocimiento y su definición formal guardan cercanía con el concepto de habitus, tal como lo define Bourdieu (1992), tanto como la definición de acontecimiento guarda alguna semejanza con la definición del mismo propuesta por Allain Badiou (2009).

El uso de los modelos y la cantidad de modelos que puede generar un productor dependen de lo que Bourdieu Ilamaría su capital cultural, del cual forma parte el habitus. Es decir, que un sujeto productor estará en mayor o menor capacidad de enfrentar 0 emplear el repertorio según su mayor o menor manejo de los modelos, de la misma manera que el lector será más o menos hábil para descifrar un texto, dependiendo de su dominio o conocimiento del repertorio, que se incrementa mediante la exposición constante al mismo. Una segunda diferencia entre los niveles de competencia respecto del manejo de los modelos radica en la capacidad de lograr el conocimiento analítico, no solamente empírico 0 aprendido de manera no sistemática y general. Dice Even-Zohar:

El conocimiento analítico resulta más frecuente cuanto más hábil es el productor y más específico el producto. A lo mejor un artesano 0 un cocinero han adquirido sus destrezas de manera sintética, mientras que un moderno industrial puede tener un conocimiento pleno de los modelos que utiliza por lo que respecta a sus componentes y a las reglas de combinación en el tiempo y el espacio. (1999, pp. 35-36)

Por lo tanto, desde esta perspectiva, lo definitivo, para otorgar literariedad al texto, es el rol del repertorio y de la institución (academia, crítica oficial, universidades 0 un saber emanado del habitus de los jugadores del campo que alcanzan hegemonía). Desde la teoría de los polisistemas, el apego al repertorio vigente, configurado por la interacción de mercado, instituciones y consumidores, significa el acceso al mercado, que hoy es global y denominamos literatura-mundo, vale decir, un mercado literario altamente heterogeneizado, en el cual las normas del consumo están configurando una literatura uniforme, apegada al repertorio (reducido) de la posmodernidad.

A propósito del repertorio, se ha señalado anteriormente que el retorno a la narratividad como elemento central, desplazando a la experimentación, sería una característica adicional de la narrativa posmoderna. Cabe una precisión formal: en los procesos culturales las obras de arte evidencian, en su composición (y de manera más marcada en aquellas producidas en el traspaso de una poética a otra), una mixtura de procedimientos. Así, en algunos casos encontraremos textos que si bien están generalmente diseñados para generar el placer de conocer una trama (esto es, privilegiar la narratividad), aún evidencian chispazos de experimentación, pero ya como parte del repertorio. La novela posmoderna hace referencia a lo canonizado, a lo académicamente reconocido como elevada técnica literaria; lo emplea, pero lo traduce al lenguaje de las masas, dosificando la aparición o la intensidad de la experimentación.

Otra característica de la literatura posmoderna es su acercamiento a géneros propios de la cultura de masas, como el policial, la novela de aventuras, el erotismo y el humor. La dimensión humana se simplifica hasta convertirse en expresión de un género prediseñado; lo que Perniola (2008) llamó sensología, es decir, la reivindicación de lo ya sentido contra el más allá evolucionista de la vanguardia. La comunidad de sentir se convierte en un vínculo que se basa y construye alrededor de la sensibilidad compartida; lo que todos pueden sentir pero que otro ya sintió por ellos. La reedición, el remake, lo repetido y la fórmula que funciona se imponen sobre la novedad perseguida por la vanguardia. Leamos, atentamente, a Perniola:

El fenómeno de lo ya sentido no equivale en absoluto a un enfriamiento, a un debilitamiento $0 \mathrm{a}$ una merma del sentir. Consiste en la socialización de la sensibilidad $y$ de la afectividad y, por ende, el surgimiento de un modo diferente de sentir. (p. 47) 
La literatura posmoderna, en contraste con la vanguardia experimental a la cual se refiere Hobsbawm, plantea ciertas reglas no explicitadas que facilitan esta aproximación entre el gran mercado y la obra literaria. Estas reglas van más allá de las generalidades epistemológicas y pueden llegar, incluso, a distinciones retóricas. Para la definición de estas nos atenemos a la caracterización de Connor en Posmodernism and literature (2004). Para Connor existen tres características que definen a la narrativa posmoderna: el manejo del tiempo como sucesión, la perspectiva unívoca del narrador y el cambio de la importancia de la orquestación o la estructura contra la exposición pictórica, lo que marca una diferencia frente al vanguardismo. En palabras de Connor, lo que ocurría en la vanguardia era que

many modernist novels are also much concerned with the multiplication of voices and perspectives and the concomitant difficulty of orchestrating those voices and perspectives. But one of the ways in which this orchestration takes place is by displacing questions of voice into questions of point of view. Rendering the question "Who speaks?" in the form of the question "Who sees?" makes it a question of a position rather than of an event. (p. 63) $)^{4}$

Por otro lado, algunas narrativas de la posmodernidad se centran más en la voz en lugar de la perspectiva o la mirada. Es un esfuerzo por construir una voz en lugar de una perspectiva y, a la vez, por "more than just changing the axis of analysis, so that, instead of attending to what is simultaneous in narrative, one would attend instead to what is successive"(Connor, 2004, p. 65) $)^{5}$.
De esta forma, el tiempo concebido como una secuencia lineal en la novela supone una trama que se desarrolla consecutivamente, en lugar de confluyentemente, y desde variadas perspectivas, como lo hace la novela modernista, de la modernidad 0 vanguardista, para evitar confusiones con periodos de denominación diversa en algunos espacios regionales.

Tenemos entonces definida la tríada de los elementos constituyentes de la narrativa posmoderna: abandono de la perspectiva múltiple, preeminencia de la secuencialidad temporal y simplificación de la estructura. Estos tres elementos constituyen lo central del repertorio de nuestra época actual. Cabría desarrollar el concepto de lo monumental, la inconmensurabilidad, atestiguada en el arte posmoderno, como la realización misma de la imposibilidad de medición o representación, contra el intento de las vanguardias por rendir cuenta de lo que no puede ser abarcado en un solo intento, desde una sola mirada, multiplicando la perspectiva, complicando la estructura y trabajando sobre el tiempo como líneas yuxtapuestas en un nuevo tiempo que es el de la novela, que, en lugar de hacerlo avanzar, lo detiene, retrocede, cuestiona ${ }^{6} . .$.

Un caso particular relativo a la mundialización de lo literario es el de las literaturas en el exilio. Físico, se sobreentiende, ya que la reducción del mundo gracias a la web, el satélite y los medios globales de comunicación, dificulta el exilio cultural. Sumamente esclarecedor sobre el destino de los autores que comparten este destino es el siguiente texto de Lambert (1999 [1988]):

El escritor ambicioso se pondrá a menudo al servicio de los nuevos grupos de prestigio, partirá para el Nuevo Mundo de los poderosos, físicamente 0 en imaginación, adoptando sus modelos literarios (la lengua, los géneros, los circuitos de difusión). Después de haber abandonado así la fidelidad (literaria) a sus ancestros, el 'nuevo' escritor puede llegar a abandonar también (físicamente 0 solo en el plano literario) su segunda patria y optar por vías deliberadamente internacionales. (p. 70)

Adjetivos aparte, hay un hálito de profecía en las palabras de Lambert.

\section{Dos ejemplos \\ del repertorio vigente: \\ La tía Julia \\ y el escribidor y Travesuras de la niña mala}

Tomemos, a manera de ejemplo, dos novelas que relatan historias de amor que se remiten a la juventud del narrador personaje en ambas. En La tía Julia y el escribidor la voz narrativa se identifica con la del personaje Marito, joven estudiante de la Universidad de San Marcos que se inicia en la literatura mientras se dedica a trabajar en varios empleos mal pagados, uno de los cuales es "un trabajo de título pomposo, sueldo modesto, apropiaciones ilícitas y horario elástico" (Vargas Llosa, 1977, p. 11).

A la línea argumental del enamoramiento y romance de Marito con la tía Julia, se contrapone, capítulo a capítulo, el desarrollo de guiones de radionovela, escritos por un personaje que se gana

4 "Muchos novelistas modernistas están también muy preocupados por la multiplicación de voces y perspectivas y la dificultad concomitante de orquestar tales voces y perspectivas. Pero una de las formas en las cuales esta orquestación tiene lugar es desplazando la pregunta sobre la voz hacia la pregunta sobre el punto de vista. Formular la pregunta “¿Quién habla?" bajo la forma de la pregunta “¿Quién ve?” genera la interrogante sobre una posición, en lugar de hacerlo sobre un suceso" (Traducción del autor).

5 "Más que simplemente cambiar el eje de análisis, de tal manera que en lugar de prestar atención a lo que es simultáneo en esa narrativa, se prestaría atención a lo que es sucesivo" (Traducción del autor).

6 En sentido contrario a este objetivo imposible de la vanguardia, tomemos una muestra del triunfo de la secuencialidad entre los múltiples productos de la mass media; éxito que se puede advertir en la enorme audiencia que ha tenido y tiene la serie televisiva 24, acerca de la cual Mario Vargas Llosa escribió un elogioso artículo. Esta serie sucede en tiempo real; la acción dura cubre veinticuatro horas y cada episodio de la serie dura una hora y reproduce lo que sucede en una hora. El tiempo real y el de la narración se organizan secuencialmente. 
la admiración del novel escritor: Pedro Camacho, creador de las alocadas historias que se transmiten en vivo desde los estudios de la radio en la cual trabaja Marito como redactor de noticias. Tanto el romance como la salud mental del escribidor se van complicando y los personajes de las radionovelas parecen tomar vida propia, desafiando incluso la mortalidad, ya que mueren y reaparecen en roles distintos en otras historias diferentes de aquella que Ios trajo a la vida radiofónica. Pedro Camacho, recluido en una institución mental, vivirá rodeado de sus personajes e inmerso en su antiargentinismo a ultranza. Estas dos líneas constituyen una contraposición de la gran literatura (que pretende escribir Marito) y la literatura de masas de Pedro Camacho, aunque la primera termine siendo un guiño a Corín Tellado.

TIEMPO Y SECUENCIAS NARRATIVAS DE LA TÍA JULIA Y EL ESCRIBIDOR

\begin{tabular}{|c|c|c|c|c|c|c|c|}
\hline T1 & T1 & T2 & T2 & T3 & T3 & T11 & T11 \\
\hline A1 & B1 & A2 & B2 & A3 & B3 & A11 & B11 \\
\hline
\end{tabular}

La estructura de la novela en cuestión es sumamente simple y responde al siguiente diagrama (Figura 1), en el cual $A$ es el episodio correspondiente a los sucesos propios del romance con la tía Julia y $B$ las inclusiones de las radionovelas en el texto.

El tiempo se desenvuelve linealmente y su gráfica es la de la flecha sobre el diagrama de las secuencias narrativas. Se notará que el T1 corresponde por igual a $\mathrm{A} 1$ y $\mathrm{B} 1$; son secuencias que ocurren en el mismo tiempo, sin ser por ello dos miradas confluyentes; es al interior de las secuencias con la letra $A$, en las cuales se hace referencia a los guiones de radio de Pedro Camacho. La narración empieza en un tiempo dado y prosigue desarrollando la historia sin los flashbacks 0 analepsis a los cuales nos tenía acostumbrados Vargas Llosa en sus anteriores novelas. Esto es una visión del tiempo de la narración, propio de la narrativa posmoderna, que retoma algunas formas previas a la vanguardia mientras desecha otras, sobre todo en el aspecto del lenguaje. El lenguaje posmoderno es claro y transparente: deja traslucir la narración, sin apostar por el virtuosismo verbal de la vanguardia ni el adorno de la literatura posterior. En cierta forma es un lenguaje heredero de la vanguardia, el lenguaje de lo coloquial que intenta recuperar el lenguaje "de la calle", ejecutando una mímesis extrema. La novela posmoderna adopta esta versión coloquialista de la vanguardia, apuesta por un lenguaje para todos, que se entienda fácilmente y deje a la vista el disfrute $^{7}$ de la lectura; no quiere generar duda o necesidad de diccionario, tampoco complicar la inteligibilidad del texto, pues su intención es narrar una historia, capturar al lector y entretenrlo. Es necesario aclarar que esta no es tarea fácil; no estamos condenando la estética posmoderna, simplemente anotamos y dejamos constancia de un hecho, una constante que puede hallarse en la producción posmoderna, dirigida a ese gran público lector-consumidor que constituye lo que Barthes denominó el grado cero $^{8}$. Esto es un cambio en el repertorio o en la opción elegida del repertorio para construir un corpus de referencia nuevo.

Otra característica importante, que contrasta con la producción anterior del autor, es que la narración avanza al ritmo que le impone una conciencia autoral manifiesta en un narrador personaje; esta conciencia única es un quiebre radical respecto del radicalismo, al escepticismo de los textos vanguardistas, en los cuales la indeterminación, el relativismo, están representados por multiplicidad de voces que presentan interpretaciones distintas del mismo suceso. En La tía Julia y el escribidor no hay lugar a esa duda. Hay una conciencia rectora, judicatora, que atraviesa el texto y le otorga sentido. La posmodernidad se vive como un tiempo en el cual los conflictos ideológicos aparecen como superados, existe un proyecto único hegemónico que interpreta el mundo y lo presenta listo para ser gozado ${ }^{9}$, lo cual puede afirmarse también con respecto al mundo novelado; no

7 El concepto del disfrute es esencial en la lógica cultural del capitalismo tardío. Es la respuesta de la configuración social al Che vuoi? lacaniano. Todos pueden acceder a su deseo, al deseo del otro, hay una comunidad en el compartir un sentido que construye una identidad instaurada como una Jouissance, goce sin cuestionamiento.

8 En El grado cero de la escritura (Barthes, 1997) se propone la teoría de que existe un nivel mínimo de performancia que hace posible el entendimiento humano, que elimina la ambigüedad y la connotación. Ese grado cero se manifiesta tanto en el habla como en la escritura, aunque, en teoría, es un imposible.

9 Cuando Žižek titula un capítulo de El sublime objeto de la ideología como "Goza tu síntoma" está reconociendo esta predigestión del mundo y sus conflictos. Si el síntoma es el achatamiento de la perspectiva, la univocidad, el criterio único es el síntoma gozado. 
hay confusión posible, está listo para ser leído.

En Travesuras de la niña mala (Vargas Llosa, 2008) la estructura se simplifica aún más, ya que es una sola línea argumental la que sustenta el pacto narrativo. Lo que une a los capítulos y les da identidad no es solamente el narrador homodiegético con focalización interna (narrador personaje), también la secuencia lineal de los sucesos que colocan en una condición similar al lector y al narrador: no se permite prolepsis, ni siquiera insinuadas, como tampoco analepsis de tipo alguno. Existe un misterio que se va develando poco a poco mediante la conversación con personajes vinculados a la infancia de la niña mala dentro de un relato singulativo ${ }^{10}$, es decir, en el cual se narra una sola vez un suceso que se reproduce por vez única en el texto. Es la estructura del relato policial clásico, otro guiño a la cultura de masas.

La simplificación del manejo del tiempo y el espacio en la novelística de Vargas Llosa obedecería a un hecho evidente, que es su ingreso en la literatura -mundo, de la que es referente central. Existe un repertorio vigente que se sostiene en un mercado, un grupo de consumidores y un productor ahora mixto, ya no es solo el novelista o escritor; en esta nueva industria literaria, el papel del editor se hace cada vez más importante, en términos de acceso y consolidación en la literatura-mundo. Para las condiciones de un mercado amplificado y masificado de lectores, novelas con complejidades estructurales y relativismos radicales como las del segundo periodo de la novelística de Vargas Llosa, supondrían un producto difícil de vender. Sin desmedro de la calidad como escritor de nuestro Nobel, su presencia en el mercado literario supone ciertas restricciones y apego al nuevo repertorio, sin embargo, sabe cómo hacer reaparecer, de vez en cuando, estas series residuales o recesivas que su talento maneja con pericia. Considero que este sería su aporte a la elevación de esa cultura masificada, acercándola a lo que llamamos la gran cultura.

El abandono del perspectivismo por una visión única que la historia entrega como algo ya dado, algo interpretado que solo requiere del lector el esfuerzo necesario para acompañar el develamiento de un misterio de forma por demás sencilla (narración de un personaje que aparece en los capítulos finales), nos sitúan en un mundo consistente con la ideología posmoderna del fin de las ideologías y de las interpretaciones. La performatividad, a nivel del lector, consiste en acompañar el evento, tomar conocimiento del suceso y participar del goce del texto.

Estas condiciones son compartidas en gran medida por las novelas escritas por Mario Vargas Llosa entre los años 1973-77 hasta el presente (2016). Existen, claro está, momentos en los cuales se producen reediciones del repertorio anterior, como una huella de hibridez en el panorama de una estética posmoderna que domina los textos ${ }^{11}$. Estas breves apariciones mantienen, no obstante, el fulgor y vigor de la narrativa de Mario Vargas Llosa, por lo que cabe suponer una elección formal consciente y adecuada al puesto en el sistema de la literatura-mundo, que le compete al autor, no solamente como premio Nobel, sino como autor nacido en la periferia que accedió a la metrópoli de las letras. No se discute en términos de rendición ante el mercado, sino de concesiones inteligentes a un universo ampliado de lectores, a Ios cuales Vargas Llosa sabe Ilegar, dosificando algunos vestigios de su periodo vanguardista, que son parte de su repertorio. En estos tiempos se ha vuelto un deporte literario jugar a la piñata con Vargas Llosa, una actitud políticamente correcta en algunos ámbitos, pero llamamos a recordar que nuestro Nobel es tanto el autor de El héroe discreto como de Conversación en La Catedraly un maestro del manejo de la estructura del relato. Reconocemos en Vargas Llosa dos apegos, el primero de ellos a su pasado literario, evidente en esos guiños que nos hace a sus lectores de siempre al incluir chispazos de su repertorio clásico en sus nuevas publicaciones y, el segundo, su pasión por el Perú. En todas las novelas que ha escrito, Vargas Llosa siempre ha cumplido con su promesa de 1967: “...yo solo escribo sobre el Perú y sólo me interesa escribir sobre el Perú"12, aunque para reflexionar sobre la dictadura de los noventa haya recurrido a la anécdota del dictador Trujillo de República Dominicana y para escudriñar el fundamentalismo, que tanto daño nos hizo, haya retomado Los sertones de Euclides D'Acunha. Cualquier escenario le es válido para regresar a nosotros.

10 En este párrafo seguimos las categorías de la narratología desarrolladas por Genette (1998).

11 Entre otros ejemplos, la notable Historia de Mayta o la recuperación de los diálogos telescópicos en Lituma en los Andes, estupenda versión del mito báquico que nuestra crítica, poco formada en mitología (en los clásicos, para decirlo con todas sus letras) no ha sabido descifrar.

12 Entrevista de M.F., aparecida en el suplemento de Imagen, núm. 6, citada por Oviedo (1982, p. 32). 


\section{Bibliografía}

Badiou, A. (2009). Segundo manifiesto por la filosofía. Buenos Aires: Manantial.

BARTHES, R. (1997). El grado cero de la escritura. Buenos Aires: Siglo XXI.

Bourdieu, P. (1995). Las reglas del arte. Génesis y estructura del campo literario. Barcelona: Anagrama.

Connor, S. (ed.). (2004). Postmodernism and literature. En S. Connor (ed.), The Cambridge companion to postmodernism (pp. 62-81). New York: Cambridge University Press.

Even-Zohar, I. (1999). Factores y dependencias en la cultura. Una revisión de la teoría de los polisistemas. En M. Iglesias (comp), Teoría de los polisistemas. Madrid: Arco/Libros.

García-Bedoya, C. (2012). Posmodernidad narrativa en América Latina. En C. García-Bedoya, Indagaciones heterogéneas. Estudios sobre literatura y cultura (pp. 113-126). Lima: Grupo Pakarina.

GenetTe, G. (1998). Nuevo discurso del relato. Madrid: Cátedra.

Hobsbawm, E. (1999). Historia del siglo xx. Buenos Aires: Grijalbo Mondadori.

Jakobson, R. (1975). Ensayos de lingüística general. Barcelona: Seix Barral.

LAMBERT, J. (1999). Aproximaciones sistémicas a la literatura en las sociedades multilingües. En I. Montserrat (comp), Teoría de los polisistemas. Madrid: Arco/Libros.

Lotman, I. (1998). La semiósfera. Semiótica de la cultura, del texto, de la conducta y del espacio (3 vols). Madrid: Cátedra.

Oviedo, J. M. (1982). Vargas Llosa: La invención de una realidad. Barcelona: Seix Barral.

Perniola, M. (2008). Del sentir. Valencia: Pre-Textos.

Vargas Llosa, M. (1959). Los jefes. Barcelona: Ediciones Roca.

VARGas LlosA, M. (1963). La ciudad y los perros. Barcelona: Seix Barral.

VARGAS LLOSA, M. (1967). Los cachorros. Madrid: Lumen.

Vargas Llosa, M. (1969). Conversación en La Catedral (2 vols). Lima: Peisa.

VARGas lLoSA, M. (1973). Pantaleón y las visitadoras. Barcelona: Seix Barral.

Vargas Llosa, M. (1977). La tía Julia y el escribidor. Barcelona: Seix Barral.

VARGAS LloSA, M. (1981). La guerra del fin del mundo. Barcelona: Seix Barral.

VARGAS LLOSA, M. (2003). El paraíso en la otra esquina. Madrid: Alfaguara.

VARGas LloSA, M. (2006). Travesuras de la niña mala. Madrid: Alfaguara.

Vargas LLoSA, M. (2010). El sueño del celta. Madrid: Alfaguara.

Vargas Llosa, M. (2013). El héroe discreto. Madrid: Alfaguara. 


\section{Anexo}

\begin{tabular}{|c|c|c|c|c|}
\hline \multicolumn{5}{|c|}{ GRÁFICA DE LOS PERIODOS EN LA NARRATIVA DE MARIO VARGAS LLOSA } \\
\hline & & OVIEDO & GARCÍA-BEDOYA & PROPUESTA \\
\hline Los jefes & 1959 & & & \\
\hline La ciudad y los perros & 1963 & & & \\
\hline La casa verde & 1966 & & & \\
\hline Los cachorros & 1967 & & & \\
\hline Conversación en La Catedral & 1969 & & & \\
\hline Pantaleón y las visitadoras & 1973 & & & \\
\hline La tía Julia y el escribidor & 1977 & & & \\
\hline La guerra del fin del mundo & 1981 & & & \\
\hline Historia de Mayta & 1984 & & & \\
\hline ¿Quién mató a Palomino Molero & 1986 & & & \\
\hline El hablador & 1987 & & & \\
\hline Elogio de la madrastra & 1988 & & & \\
\hline Lituma en los Andes & 1993 & & & \\
\hline Los cuadernos de don Rigoberto & 1997 & & & \\
\hline La Fiesta del Chivo & 2000 & & & \\
\hline El paraíso en la otra esquina & 2003 & & & \\
\hline Travesuras de la niña mala & 2006 & & & \\
\hline El sueño del celta & 2010 & & & \\
\hline El héroe discreto & 2013 & & & \\
\hline Cinco esquinas & 2016 & & & \\
\hline
\end{tabular}

En contraste con otras periodizaciones, diferenciamos un periodo formativo, luego otro de vanguardismo experimentalista, seguido de un periodo transicional en el cual se insertan algunos elementos de la mass culture. Dividimos el periodo posvanguardista o posmodernista en un momento que manifiesta cierto vanguardismo residual y, finalmente, un periodo posvanguardista o posmodernista. La ciudad y los perros es una obra bisagra, anuncia el vanguardismo extremo del periodo siguiente, sin ser abiertamente vanguardista. 